\title{
Antibiogram of Methicillin- Resistant Staphylococcus aureus Isolates among Healthy Human Subjects in Oleh, South-Southern Nigeria
}

\author{
C. O. Anie ${ }^{1}$, M. C. Ugwu ${ }^{2 *}$, E. C. Ibezim ${ }^{3}$ and C. O. Esimone ${ }^{2}$ \\ ${ }^{1}$ Faculty of Pharmacy Delta state University, Abraka Delta State, Nigeria \\ ${ }^{2}$ Department of Pharmaceutical Microbiology and Biotechnology, Nnamdi Azikiwe University, \\ Awka, Anambra State, Nigeria \\ ${ }^{3}$ Department of Pharmaceutics, Faculty of Pharmaceutical Sciences, University of Nigeria, \\ Nsukka, Enugu State, Nigeria \\ *Corresponding author
}

\begin{tabular}{|c|c|}
\hline & A B S T R A C T \\
\hline & \multirow{6}{*}{$\begin{array}{l}\text { Methicillin-resistant Staphylococcus aureus (MRSA) is one of the major causes of } \\
\text { hospital-acquired infections worldwide. It is widespread in communities and prevalent in } \\
\text { hospital and even amongst the livestock.The mortality and morbidity amongst patients } \\
\text { with infections associated with MRSA are usually high owing to increasing resistance to } \\
\text { several antibiotics. The resistant pattern of MRSA has not been clearly defined in Oleh. } \\
\text { This study was designed to determine the incidence and antibiotics resistant pattern of } \\
\text { MRSA from the healthy students in Oleh campus, south-southern Nigerian locality. } \\
\text { Methods: Three hundred (300) specimens were collected and appropriate procedures were } \\
\text { followed for identification and susceptibility testing. The MRSA was determined using } \\
\text { Oxacillin antibiotic disc. Of the } 300 \text { nasal swab samples collected and screened, a total } 164 \\
\text { ( } 72.7 \% \text { ) of the isolates were found to be } S \text {. aureus based on morphology and biochemical } \\
\text { tests. The incidence rate from female to male individuals were } 78(57 \%) \text { and } 87 \text { (52 } \% \text { ) } \\
\text { respectively. The incidence rate of MRSA and colonisation among healthy individuals in } \\
\text { the community was } 15.7 \% \text { ( } 47 / 300 \text { ) and } 28.7 \% \text { ( } 47 / 164) \text { of the } S \text {. aureus isolates. The } \\
\text { antibiotic resistant pattern of MRSA isolates was ciprofloxacin } \sim \text { ofloxacin } \sim \text { amoxicillin } \\
\text { clavulanate }>\text { gentamicin, co-trimoxazole > chloramphenicol }>\text { erythromycin }> \\
\text { streptomycin >amoxicillin Although, multi-drug resistant strains of } S \text {. aureus have been } \\
\text { identified in this study, infections caused by } S \text { aureus infections could be treated with } \\
\text { flouroquinolones and Gentamicin. }\end{array}$} \\
\hline Keywords & \\
\hline $\begin{array}{l}\text { MRSA, Resistance, } \\
\text { antibiotics } \\
\text { susceptibility, } \\
\text { tertiary Students, } \\
\text { Delta state }\end{array}$ & \\
\hline Article Info & \\
\hline $\begin{array}{l}\text { Accepted: } \\
\text { 20 July } 2017 \\
\text { Available Online: } \\
\text { 10 September } 2017\end{array}$ & \\
\hline & \\
\hline
\end{tabular}

\section{Introduction}

Staphylococcus aureus is one of the common Gram positive bacterial pathogens significantly contributing to hospital and community-acquired infections globally (Ugwu et al., 2016). Frequent use of antibiotics has modified $S$. aureus antibiotic susceptibility to methicillin and related antibiotics such that strains that were methicillin-sensitive (MSSA) have become Methicillin-resistant Staphylococcus aureus (MRSA (Rosina et al.,2017). A strain of $S$. aureus is said to be MRSA when is resistant to a methiccilin, oxacillin and vancomycin (Ike et al., 2016). MRSA started as hospitalacquired, but has reached a pandemic status and now it is community-acquired and 
livestock-acquired with a consequent potential epidemiological shift in staphylococcal infections (Akerele et al., 2015, Kejela and Bacha, 2013, Som and Chatterrjel 2013). Antibiotics misuse, prolonged hospitalization and nasal carriage of MRSA are recognized risk factors for MRSA acquisition and spread (Oomen et al., 2010, Wertheim 2004) MRSA can colonize healthy people at a reduced rate $(<8 \%)$ and represents a potent and prevalent risk factor for subsequent $S$. aureus infections (Ugwu et al., 2016, Som and Chatterjel 2013). Nasal carriers of MRSA are susceptible to wound infections, increased the likelihood of invasive disease and occasionally toxic shock syndrome (Ugwu et al., 2016,Ilejela et al., 2017, Okwu et al., 2009, Ugwu et al., 2009). MRSA plays crucial role in community diseases acquisition and there has been a global increase in the number of MRSA infections [(Okwu et al., 2012, Som and Chatterjel,2013).Many infections that are difficult to treat are attributed to MRSA and is known to contribute to extended periods of hospitalization, high costs of treatment, as well as mortality rate (Ugwu et al.,2016,Ike et $a ; l ., 2016)$ Epidemiological data in the human population suggest that there is a rise in CAMRSA carriage(Som and Chatterjel 2013).

CA-MRSA is a significant public health burden and it is endemic in most countries [Som and Chatterjel 2013, Moellering 2006, Skov 2012). In developing settings e.g. Nigeria, CA-MRSA poses a serious therapeutic challenge. The mechanism of their emergence as well spread in the community is sparsely documented (Cheesbrough 2004). Thus, in order to implement strategies for the effective containment of MRSA carriage, it is necessary to characterize isolates at the community level. This will provides useful baseline information as CA-MRSA colonization has been reported as one of the risk factors for MRSA dissemination (Ugwu et al., 2016). Data concerning the frequency of nasal carriage of MRSA in the Ole community is not known. Therefore, we designed this study to evaluate the prevalence and antibiotic susceptibility profile of MRSA among healthy tertiary Students in Oleh, South-southern Nigeria.

\section{Materials and Methods}

\section{Sample collection/purification, Isolation} and identification of Test Bacteria

This study was conducted in Delta University State University Oleh campus. The nasal samples were obtained with sterile swab sticks and Individual swab was adequately labelled and was immediately inoculated on mannitol- salt agar procured from Oxoid (England) and incubated for $18-24 \mathrm{~h}$ at $37^{\circ} \mathrm{C}$. Pure culture of each isolate was obtained by streak plate technique. Identification of isolates were by colony morphology, Gram staining,catalase test and coagulase test (Ugwu et al., 2016). Thereafter, isolates that were positive to Gram staining, catalase and coagulase tests were considered as $S$. aureus [Ugwu et al., 2016, Ike et al., 2016 Cheesbrough 2004].

\section{Phenotypic screening of S.aureus for Methicillin resistance using the Oxacillin disc}

Susceptibility of the S.aureus isolates was done by means of the agar diffusion method on Muller Hinton agar using Oxacillin (1 mcg) sensitivity disc. The isolates were standardized to 0.5 Mcfarland standards and suspension of which was aseptically inoculated on the Muller Hinton agar plates. The plates were incubated for 18-24 hours at $37^{\circ} \mathrm{C}$.Therefater, the zones of inhibition were measured and interpreted using to Clinical laboratory standard institutes (CLSI) breakpoint [CLSI,2016] 


\section{Phenotypic screening of VRSA using the Vancomycin disc}

This was done by agar diffusion method on Muller Hinton agar using Vancomycin (30mcg) sensitivity disc The standardized suspension of the isolates was inoculated aseptically onto the Muller Hinton agar plates and Vancomycin (30mcg) sensitivity disc placed aseptically on the surfaces. The plates were incubated for 24 hours at $35-37{ }^{\circ} \mathrm{C}$. Then the zones of inhibition were recorded and interpreted [CLSI, 2016].

\section{Antibiotic susceptibility testing (AST)}

The antibiogram of the isolates was determined against some commonly used antibiotics using disc diffusion method following the CLSI guidelines. The antibiotic discs contained the following antibiotics and concentrations; Gentamycin $10 \mu \mathrm{g}$; Amoxicillin $\quad 30 \mu \mathrm{g} ; \quad$ Vancomycin,Cotrimoxazole Ciprofloxzcin 10 $\mu \mathrm{g}$; Ofloxacin: Streptomicin $30 \mu \mathrm{g} ; \quad$ Co-trimoxazole $30 \mu \mathrm{g}$; Erytbromycin $10 \mu \mathrm{g}$. Isolates were classified as either resistance or intermediate or sensitive according to the CLSI (2016)

\section{Results and Discussion}

Table 1 shows the incidence of $S$. aureus among males and females of the tertiary institution in Oleh locality in Delta State. Characterization studies revealed that $66.7 \%$ (64/300) of the three hundred (300) nasal samples screened, were to be $S$. aureus. The incidence of $S$. aureus among female to male individuals were $52(\%)$ and 57 (\%) respectively. The incidence rate of MRSA colonization among healthy subjects in the studied community of the $S$. aureus isolated was $15.7 \%$ (47/300) (as shown in Table 2.

The antibiotic susceptibility pattern of MRSA is shown in Table 3. Ciprofloxacin, ofloxacin and Amoxicillin-clavulanic acid had the best anti-staphylococcal activities, with five (5) isolates resistant to these agents, while 42 isolates were susceptible. Seven (7) isolates were resistant to gentamicin while 40 isolates were susceptible to it. Eight (8) of the isolates were resistant to amoxicillin clavulanate antibiotic while 39 isolates were susceptible. Co-trimoxazole has 10 isolates resistant to it, while 37 MRSA isolates were susceptible. Twenty isolates were resistant to chloramphenicol, while 27 isolates were susceptible. For erythromycin, 23 isolates were resistant, while 24 isolates were susceptible. Greater number of the isolates was resistant to streptomycin with 27 isolates resistant to it while 20 isolates were susceptible. Similarly, amoxicillin had the highest number of isolates (37) resistant to it, while only 10 isolates were susceptible. Summarily, the pattern of susceptibility of antibiotic to MRSA was as follows: ciprofloxacin $\sim$ ofloxacin $\sim$ amoxicillin clavulanate $>$ gentamicin, $>>$ co-trimoxazole $>$ chloramphenicol $>$ erythromycin > streptomycin >amoxicillin

There have been reports of Strains of CAMRSA that cause infections in healthy people and CA-MRSA infections are on the increase in various regions and countries (Ugwu et al., 2016). CA-MRSA continues to be a major global health challenge due to the presence of multiple drug resistant encoding genes (Ugwu et al., 2016, Ike et al., 2016, Onanuga et al., 2005). We are not aware of any published data on the nasal carriage of MRSA in Oleh campus of Delta state Nigeria.

This study evaluated the prevalence as well as the antibiotic susceptibility profile of MRSA among healthy tertiary Students in Oleh, South-southern Nigeria.

The carrier rate of $S$. aureus in this study was $54.7 \%$ (164/300) made up of $28.7 \%$ (male) and $26 \%$ (female). 
Table.1 Frequency of isolation $S$ aureus among healthy students of DELSU Oleh

\begin{tabular}{|l|l|l|l|}
\hline Source & Number sampled & Number of S.aureus Isolated & Percentage (\%) \\
\hline Male & 150 & 86 & 57 \\
Female & 150 & 78 & 52 \\
\hline Total & 300 & 164 & 55 \\
\hline
\end{tabular}

Table.2 Incidence of MRSA among healthy students of DELSU Oleh

\begin{tabular}{|l|l|l|}
\hline SOURCES & Frequency of MRSA & Percentage $(\boldsymbol{\%})$ \\
\hline Male & 24 & 51.1 \\
\hline Female & 23 & 48.9 \\
\hline Total & 47 & 100 \\
\hline
\end{tabular}

Table.3 Antibiotic Susceptiblity pattern of MRSA isolates from nasal swabs of healthy students of DELSU, Oleh

\begin{tabular}{l|l|l|l|l|} 
Antibiotic & \multicolumn{2}{c}{ Number Resistant } & \multicolumn{2}{c|}{ Number Susceptible } \\
\hline $\begin{array}{l}\text { Amoxicillin } \\
\text { Amoxicillin- }\end{array}$ & Number(n) & Percentage (\%) & Number(n) & Percentage (\%) \\
Clavulanic acid & 5 & 78.8 & 10 & 21.3 \\
Chloramphenicol & 20 & 10.6 & 42 & 89.4 \\
Ciprofloxacin & 5 & & & 57.5 \\
\hline Co-trimoxazole & 10 & 42.6 & 27 & 89.4 \\
Erythromycin & 23 & 10.6 & 42 & 78.7 \\
Gentamicin & 7 & 21.3 & 37 & 51.1 \\
Ofloxacin & 5 & 48.9 & 24 & 85.1 \\
Streptomycin & 27 & 14,9 & 40 & 89.4 \\
\hline
\end{tabular}

Colonization rate of $S$. aureus between the sex was not statistically significant $(\mathrm{P}>0.05)$. Similar no statistical significant difference in colonization rate of $S$. aureus between the male and female category have been reported in Agbor (South-southern Nigeria), in Jos, (North-central Nigeria), in Okada, South west Nigeria (Ugwu et al.,2016 Okwu et al., 2012 Ajoke et al., 2012) and in Riyadh, Saudi Arabia (Alaklobi et al., 2015). The studies all maintained that sex is not a notable determinant in $S$. aureus colonization. The incidence rate of MRSA nasal colonization among healthy individuals in the studied community of was $15.7 \%$. This rate is similar to $18.7 \%$ recorded by our team among Healthy Students in Agbor, another Southsouthern Nigerian locality (Ugwu et al., 2016). However, the rate of CA-MRSA in this locality is a concern because: (i) Colonization has severally been reported to be a significant aspect of the events that leads to S. aureus infections and transmission. Subjects are first colonized, invaded and are finally infected [Ugwu et al.,2016 (Alaklobi et al., 2015,Ugwu et al., 2015] (ii) CA-MRSA has been reported to be more virulent than the hospital counterpart (Braga et al.,2014, Mahde et al.,2017, Ugwu et al.,2013). Virulence factors such as production of 
toxins, possession of antibody inactivating cell-surface proteins as well as high transmission rates are the hallmarks of CAMRSA strains (Nwafal et al., 2015). The ability of CA-MRSA to spread from person to person is well established and occurs frequently in closed populations (schools or sport facilities) (Nwafal et al.,2015, Van et al.,2013).

The antibiotic susceptibility pattern of MRSA was as follows: ciprofloxacin ofloxacin amoxicillin clavulanate $>$ gentamicin, $>>$ cotrimoxazole > chloramphenicol > erythromycin $>$ streptomycin >amoxicillin.

This pattern is in line with similar studies from Nigeria as well as other countries as high level of resistance to Amoxicillin, chloramphenicol and erythromycin have previously been reported ([Okwu et al., 2012, Ugwu et al., 2015). The increasing prevalence of multidrug resistant CA-MRSA is of potential epidemiological threat with clinical and pharmacological implications. The resistant genes can be transferred to other potential pathogens (Ugwu et al., 2013)

The observed improved activity of the Amoxicillin-Clavulanic acid over Amoxicillin against the MRSA is worthy of note. The weakness associated with Amoxicillin class is related to their $\beta$-lactam chemical ring nucleus which has been compromised by activities of $\beta$-lactamase. The enhancement of the activity of Amoxicillin in the Clavulanic acid -complex is thus attributed to the protection by Clavulanic acid (Ugwu et al., 2009). The observed high MRSA susceptibility to flouroquinolones (Ciprofloxacin, Ofloxacin), and gentamicin in this study is line with other published studies [Ajoke et al., 2012, Ugwu et al., 2015] Research, has shown that Agents which produce their antibacterial effect through inhibition of protein synthesis and DNA gyrase are active against staphylococcal infections (Ugwu et al., 2015).

The rate of CA-MRSA carriage among healthy subjects in Oleh was within the range reported regionally and nationally. Protein synthesis and DNA gyrase inhibitors should be considered in subjects with suspected moderate to severe $S$. aureus infections and for empiric MRSA coverage.

We equally recommend that there should be increased use of disinfectants, promotion of proper sanitary measures as well as improved and frequent hand washing practices in the institution as part of Staphylococcal infection control measures in the institution.

\section{References}

Ajoke, O.I., Okeke, I.O., Odeyemi, O.A., Okwor S. 2012. Prevalence of methicillin-resistant Staphylococcus aureus from healthy community individuals volunteers in Jos south, Nigeria. Journal of Microbiology, Biotechnology and food scienses 1: 1389-1405.

Akerele, J.O., Obasuyi, O., Omede, D. 2015. Prevalence of methicillin-resistant Staphylococcus aureus among healthy residents of Ekosodin Community in Benin-City, Nigeria. Trop J Pharm Res 14(8): 1495-9.

Alaklobi, F., Aljobair, F., Alrashod, A.,, Alhababi, R.,, Alshamrani, M., Alamin, W., Lyubov, L., Alrouki,.,F, Mertz, D. 2015. The prevalence of communityassociated methicillin-resistant Staphylococcus aureus among outpatient children in a tertiary hospital: A prospective observational study in Riyadh, Saudi Arabia. International Journal of Ped, and Adol. Med. 2, 136140

Braga, E.D., Aguiar-Alves, F., de Freitas 
Mde F; de e Silva, M.O., Correa, T.V., Snyder, R.E. Cardoso C.A. 2014. High prevalence of Staphylococcus aureus and methicillin-resistant $S$. aureus colonization among healthy children attending public daycare centers in informal settlements in a large urban center in Brazil. BMC Infect. Dis., 14: 538

Cheesbrough, M., District laboratory practice in tropical countries. Cambridge 374 University Press UK 2004; pp. 136-42.

Clinical Laboratory Standard Institute, CLSI. Performance Standards for Antimicrobial Susceptibility Testing; document M100 26th.

Ike, B., Ugwu, M.C., Ikegbunam, M.N., Nwobodo, D., Ejikeugwu, C., Gugu, T., Esimone C.O. 2016. Prevalence, Antibiogram and Molecular Characterization of Comunity-Acquired Methicillin-Resistant Staphylococcus Aureus in AWKA, Anambra Nigeria. The Open Microbiol Journal, 10: 211221

Kejela, T., Bacha, K. 2013. Prevalence and antibiotic susceptibility pattern of methicillin-resistant Staphylococcus aureus (MRSA) among primaryschool children and prisoners in Jimma Town, Southwest Ethiopia. Ann Clin Microbiol Antimicrob 12: 11.

Mahde, S.A., Reem, F.P., Nawfa, R.H., Ahmed, H.H., Araz R.I. 2017. The prevalence of $S$. aureus nasal colonisation and its antibiotic sensitivity pattern amongst primary school pupils. Science Journal of University of Zakho 5(1): $7-10$,

Moellering, R.C., Jr. The growing menace of community-acquired methicillinresistant Staphylococcus aureus. Ann Intern Med. 2006; 144:368-370.

Nawfal, R., Hussein, Z.B., Ary H. M., Samim, A., Al-Dabbagh. 2015. Comparative Evaluation of MRSA
Nasal Colonization Epidemiology in the Urban and Rural Secondary School Community of Kurdistan, Iraq. PLOS ONE, 1-9 DOI: 10.1371

Okwu, M., Bamgbala, S., Aborisade, W. 2012. Prevalence of Nasal Carriage of Community-associated

Methicillinresistant Staphylococcus aureus (CA-MRSA) among Healthy Primar School Children in Okada, Nigeria. Jou of Nat. Scs. Res2: 61-67.

Onanuga, A., Oyi, A.R., Onaolapo, J.A. 2005. Prevalence and susceptibility pattern of methicillin resistant Staphylococcus aureus isolates among healthy women in Zaria, Nigeria. Afri. Journ of Biotech 4 (11): 1321-1324,

Oommen, S.K., Appalaraju, B., Jinsha, K. 2010. Mupirocin resistance in clinical isolates of staphylococci in a tertiary care centre in south India. Indian Jour of Medical Microb, 28(4): 372-5

Rosina, G., Estifanos, K. 2007. Nasal carriage and drug sensitivity of Staphylococcus aureus among healthy Workers of Jimma University Specialized Hospital, Southwestern Ethiopia", Ethiopian J Health Scs. 17(2): 224- 228.

Skov, R., Christiansen, K., Dancer, S.J., et al., 2012. Update on the prevention and control of community-acquired meticillin-resistant Staphylococcus aureus (CA-MRSA). Int J Antimicrob Agents., 39:193-200

Som, S., Chatterjee M.O. Improved understanding of factors driving methicillin-resistant Staphylococcus aureus epidemic waves. Clin. Epidemiol 2013; 5 :205-217

Ugwu, M.C., Anie, C.O., Ibezim, E.C., Esimone, C.O. 2016. Antimicrobial Evaluation of Methicillin-Resistant Staphylococcus Aureus Nasal Carriage amongst Healthy Students in Agbor, Delta State, Nigeria. Archives of Clin Microbiol, 7 (.2):13-1-4i 
Ugwu, M.C., Ikegbunam, M.N., Nduka, S.O., Attama, A.A., Ibezim, E.C., Esimone C.O. 2013. Molecular characterization and efficacy of antibiotic combinations on multiple antibiotic-resistant Staphylococcus aureus isolated from nostrils of healthy human volunteers. Pharm Sci Res 5(1): 26-32.

Ugwu, M.C., Mokwe, N., Ejikeugwu, P.C., Gugu, T.H., Enemor, E.C., et al., 2015. Antibiogram of Staphylococcus Aureus from Healthy School Pupils in Agulu, Southeastern Nigeria. Int Jou of Res in Pharma and Bioscs; 2: 5-9.

Ugwu, M.C., Odimegwu, DC, Ibezim, E.C., Esimone, C.O 2009. Antibiotic resistance patterns of Staphylococcus aureus isolated from nostrils of healthy human subjects in a southeastern Nigerian locality. Maced J of Med Sci 12: 294-300.

Van Rijen, M.M., Kluytmans-van den Bergh, M F., Verkade E.J., Ten Ham, P.B., Feingold B.J., et al., 2013. Lifestyleassociated risk factors for community-acquired methicillinresistant Staphylococcus aureus carriage in the Netherlands: an exploratory hospital-based case-control study. PloS One. 8: e65594. PMID: 23840344

Wertheim, H.F., Vos, M.C., Ott, A, van Belkum A, Voss, A. et al., 2004 Risk and outcome of nosocomial Staphylococcus aureus bacteraemia in nasal carriers versus non-carriers. Lancet. 364: 703-705.

\section{How to cite this article:}

Anie C. O., M. C. Ugwu, E. C. Ibezim and Esimone C. O. 2017. Antibiogram of MethicillinResistant Staphylococcus aureus Isolates among Healthy Human Subjects in Oleh, SouthSouthern Nigeria. Int.J.Curr.Microbiol.App.Sci. 6(9): 3710-3716. doi: https://doi.org/10.20546/ijcmas.2017.609.458 